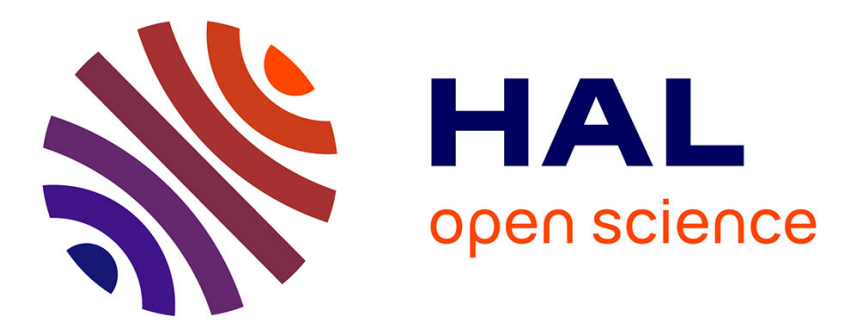

\title{
Conceptualising Gamification Risks to Teamwork within Enterprise
}

\author{
Abdullah Algashami, Sainabou Cham, Laura Vuillier, Angelos Stefanidis, \\ Keith Phalp, Raian Ali
}

\section{To cite this version:}

Abdullah Algashami, Sainabou Cham, Laura Vuillier, Angelos Stefanidis, Keith Phalp, et al.. Conceptualising Gamification Risks to Teamwork within Enterprise. 11th IFIP Working Conference on The Practice of Enterprise Modeling (PoEM), Oct 2018, Vienna, Austria. pp.105-120, 10.1007/9783-030-02302-7_7 . hal-02156453

\section{HAL Id: hal-02156453 \\ https://hal.inria.fr/hal-02156453}

Submitted on 14 Jun 2019

HAL is a multi-disciplinary open access archive for the deposit and dissemination of scientific research documents, whether they are published or not. The documents may come from teaching and research institutions in France or abroad, or from public or private research centers.
L'archive ouverte pluridisciplinaire HAL, est destinée au dépôt et à la diffusion de documents scientifiques de niveau recherche, publiés ou non, émanant des établissements d'enseignement et de recherche français ou étrangers, des laboratoires publics ou privés. 


\title{
Conceptualising Gamification Risks to Teamwork within Enterprise
}

\author{
Abdullah Algashami, Sainabou Cham, Laura Vuillier, Angelos Stefanidis, Keith \\ Phalp, Raian Ali \\ Bournemouth University, United Kingdom \\ \{aalgashami, scham, lrenshawvuillier, astefanidis, kphalp, rali\}@bournemouth.ac.uk
}

\begin{abstract}
Gamification in businesses refers to the use of technology-assisted solutions to boost or change staff attitude, perception and behaviour, about the individual or collective goals and tasks. Previous research indicated that gamification techniques could introduce risks to the business environment, and not only fail to make a positive change, but also raise concerns about ethics, quality of work, and well-being in a workplace. Although the problem is already recognised in principle, there is still a need to clarify and concretise those risks, their factors and their relation to the gamification dynamics and mechanics. In this paper, we focus on gamification risks related to teamwork within the enterprise. To address this, we conducted three-stage empirical research in two large-scale businesses using gamification in their workplace, including two months' observation and interview study. We outline various risk mitigation strategies and map them to primary types of gamification risks. By accomplishing such conceptualisation, we pave the way towards methods to model, detect and predict gamification risks on teamwork and recommend design practices and strategies to tackle them.
\end{abstract}

Keywords: Gamification, Risk Assessment, Human Factors in Computing.

\section{Introduction}

Gamification is used in workplaces to increase staff desire toward implementing tasks and achieving certain goals. The set of rewarding and gaming mechanics used in gamification includes leaderboards, badges, points, avatars reflecting individual and collective performance, levels and status. An example of gamification techniques in a call centre may involve giving rewards to individual staff members or teams based on the amount and speed of answered calls and customer feedback. Despite the benefits, applying gamification in the enterprise has potential risks. For example, the way of calculating, assigning, and displaying rewards may increase the chance for adverse work ethics including free-riding, work intimidation, and lack of group cohesion [1, 2]. Despite the recognition of these risks, no reference models and systematic methods, to the best of our knowledge, have been developed to evaluate and mitigate these risks [39]. These risks have a peculiar nature due to their intermingled relation with human factors such as motivation, personality, enterprise culture and group dynamics. 
Risk management is a subject of research in various areas, including information systems, business process management, and enterprise modelling [3-6]. Risks modelling has been studied in various settings, such as in small and medium enterprises where risks should be captured and represented alongside the various stages of the system analysis and design lifecycle [7]. Risk management has also been studied within the area of business process management for their effect on the flow of operation and its decisions [6]. It has also been argued that the concern for compliance risks and operational risks should be incorporated during the design-time and also run-time stages of business processes [8]. Risks considered in enterprise modelling literature are mainly related to mainstream requirements such as security, privacy, compliance and capability [8,9]. Gamification engineering methods, reviewed in [10], are mainly focused on providing steps and techniques for designing the game mechanics in the first place and tend to overlook their risks.

Gamification risks have a unique nature in comparison to risks typically studied in information systems literature. Ethical concerns and negative connotations of gamification as being an exploitation tool are increasingly becoming a primary concern when deciding to adopt gamification solutions in enterprises. In [11] Kumar and Herger identified five steps towards the design of such motivational systems and their game elements and named the approach as "Player Centred Design". The emphasis is on the awareness of ethical considerations in the design process. In [12] Apter and Kerr highlighted the unwanted effects - such as stress and anxiety - resulting from pressures for efficiency through the application of gamification on staff daily tasks. Thiebes et al. [13] conducted a systematic literature review on design for motivation through gamification and found that research on the risks of these elements is still in its infancy and opens the way for more research in the area.

Risks of a gamification systems applied in an enterprise stem mainly from their usage or perceived usage as an appraisal and performance monitoring mechanism, as well as a pressure tool to perform better. Gamification elements can be used to motivate individuals via self-monitoring and self-comparison. For example, a progress bar can be used to encourage delivery staff to distribute a parcel within a specific time frame and following a specific process by showing them their current status and the remaining time and stages. Peer-comparison is another modality which can increase the perception of gamification as a pressure or intimidation tool. This includes elements like leaderboards, levels and badges assigned to individuals but visible to all team members and meant to motivate by reflecting and acknowledging individual metrics, such as customers' feedback on them.

Despite the recognition of potential side-effects of gamification, factors that contribute to these risks still need to be identified and conceptualised in a comprehensive and concretised style. In this paper, we conceptualise the main factors of risks in a gamification systems to the teamwork in an enterprise. Also, we sketch a mapping between a set of mitigation strategies which we proposed in [14] and our identified gamification risks. By doing that, we take the first step towards a systematic method for gamification risk elicitation, assessment, and mitigation within the enterprise. 


\section{Research Method}

We conducted a three-stage empirical study employing multiple data collection methods from different sources aiming to increase the diversity and the credibility of the results. We adopt a multi-methods qualitative approach [15]. We summarise our method in Table 1.

In the exploration stage, we first identified a preliminary set of risks of digital motivation in its different versions, including gamification [16], game with purpose [17] and persuasive technology [18]. This was mainly informed by literature in risk assessment and management [19], value sensitive design [20], and group dynamics [21]. The identified risks were used as a template to guide a secondary analysis of data collected via interviews with experts, managers and end users in gamification related field. The primary analysis results were published in $[1,14,22]$ and were meant for good engineering practices towards accountable design and ethics of gamification in general. We created a taxonomy of risks about gamification elements and used it as a basis for ten further interviews with specialists in computing, social informatics, and psychology, as well as practitioners and managers from selected business workplaces. From these interviews, we developed a more refined set of risks factors and mitigation strategies to be explored further in the second stage.

The second stage, the confirmation and enhancement stage, aimed to confirm the results of the first stage and to identify further gamification risk elements, as well as factors and situations which contribute to their emergence. To this end, an observational study was conducted in two gamified call centres in two large multinational businesses. The total duration of observations was two months, consisting of a month in each company. By observing two companies, we increased the chance of identifying different practices of gamification elements in different populations. Each of the call centres included over 50 staff. The first belonged to a tourism company, while the second to a telecommunication company. The setup in both call centres featured agents in their private cubicle offices, answering customer calls using headphone and a screen. Agents were distributed into teams on a self- constructed basis, motivated by their collective performance. A member of the research team interviewed an experienced supervisor in each centre to learn about the environment, the workflow, the gamification techniques used, real statistics, and qualitative analysis of achieved results. Gamification mechanics used in the first call centre included leaderboards for teams' collective performance and badges sent by the supervisors based on individual performance. The second call centre used a point system in which each team worked collectively to solve customer issues and gain points which lead to a $10 \%$ increase in salaries at the end of the month for the winning team. Also, the names and photos of staff in the winning team were displayed in an honour board visible to all. In both companies, the role played by the researcher was a participant as observer [23] to observe the actual work environment, collect data, and have discussions with both call agents and supervisors during the observation period.

The third stage was designed to (i) clarify the results of the first and the second stages and to (ii) map between the risks discovered through these stages and a set of 22 risk mitigation strategies which we proposed in [14] and meant to detect and man- 
age the potential effects of gamification on teamwork. To achieve the first purpose, we conducted interviews with agents, supervisors and managers in the workplace, to clarify the results of the observation study which were themselves elaboration refinement and extension of the results of the exploratory phase. The interviews followed a semi-structured style. Fifteen interviews were conducted with ten agents, three supervisors and two managers. To achieve the second purpose of this stage, a focus group was conducted with seven participants from diverse backgrounds to map the 22 strategies to a set of identified risks of gamification to enterprise teamwork. At the start of the focus group, participants were given a presentation to familiarise them with the context. Also, they were given scenarios to immerse them in the problem and its context. They were asked to use card sorting and map the strategies given in cards with another set of cards containing the risks. The results are discussed in Section 4. Qualitative data collected in the studies were content analysed according to the six phases of thematic analysis proposed in [24]. All studies were reviewed and approved by the Bournemouth University Research Ethics Committee.

Table 1. Research Method Stages

\begin{tabular}{|c|c|c|c|c|}
\hline \multicolumn{2}{|c|}{$1^{\text {st }}$ Stage } & $2^{\text {nd }}$ Stage & \multicolumn{2}{|c|}{$3^{\text {rd }}$ Stage } \\
\hline \multicolumn{2}{|c|}{ Exploration } & Confirmation & Clar & cation \\
\hline $\begin{array}{c}\text { Secondary anal- } \\
\text { ysis \& Litera- } \\
\text { ture review }\end{array}$ & Interviews & Observation & Interviews & Focus Group \\
\hline $\begin{array}{l}\text {-Review of the } \\
\text { related literature } \\
\text { on: } \\
\text { Gamification } \\
\text { ethics, } \\
\text { Risk assessment } \\
\text { in information } \\
\text { systems, } \\
\text { Game Mechanics, } \\
\text { Group Dynamics } \\
\text { - Secondary } \\
\text { analysis of data } \\
\text { gathered in pre- } \\
\text { vious work con- } \\
\text { ducted in } \\
\text { [1, 14, 22] }\end{array}$ & $\begin{array}{l}\text { Interviews with } \\
\text { ten experts in } \\
\text { various related } \\
\text { fields: } \\
\text { - Two, experts } \\
\text { in computing } \\
\text { and social in- } \\
\text { formatics } \\
\text { - Four, experts } \\
\text { in psychology } \\
\text { and cyber- } \\
\text { psychology } \\
\text { - Two, practi- } \\
\text { tioners } \\
\text { - Two, manag- } \\
\text { ers }\end{array}$ & $\begin{array}{l}\text { Two months in two } \\
\text { call centres belong- } \\
\text { ing to: } \\
\text { - Tourism agency } \\
\text { established for } 40 \\
\text { years with over } 50 \\
\text { call agents. } \\
\text { - Telecommunica- } \\
\text { tion company has } \\
\text { over } 19 \text { years of } \\
\text { experience and } \\
\text { more than } 50 \text { call } \\
\text { agents. }\end{array}$ & $\begin{array}{l}\text { Fifteen Inter- } \\
\text { views in two } \\
\text { business } \\
\text { companies: } \\
\text { - Ten, call } \\
\text { agents } \\
\text { - Three, } \\
\text { Supervisors } \\
\text { - Two, Man- } \\
\text { agers }\end{array}$ & $\begin{array}{l}\text { Seven Partici- } \\
\text { pants from } \\
\text { various back- } \\
\text { grounds: } \\
\text { - Two, Re- } \\
\text { quirements } \\
\text { Engineering } \\
\text { - Two, Hu- } \\
\text { man- } \\
\text { Computer } \\
\text { Interaction } \\
\text { - One, User } \\
\text { Modelling } \\
\text { - One, Cyber- } \\
\text { Psychology } \\
\text { - One, Busi- } \\
\text { ness Man- } \\
\text { agement }\end{array}$ \\
\hline
\end{tabular}

\section{Gamification Risks and Risks Factors}

We identified five main classes of risk factors, summarised in Fig. 1, which are related to performance, societal and personal, goals, tasks and gamification elements. Main risks associated with these factors are written in underline and italic text. 


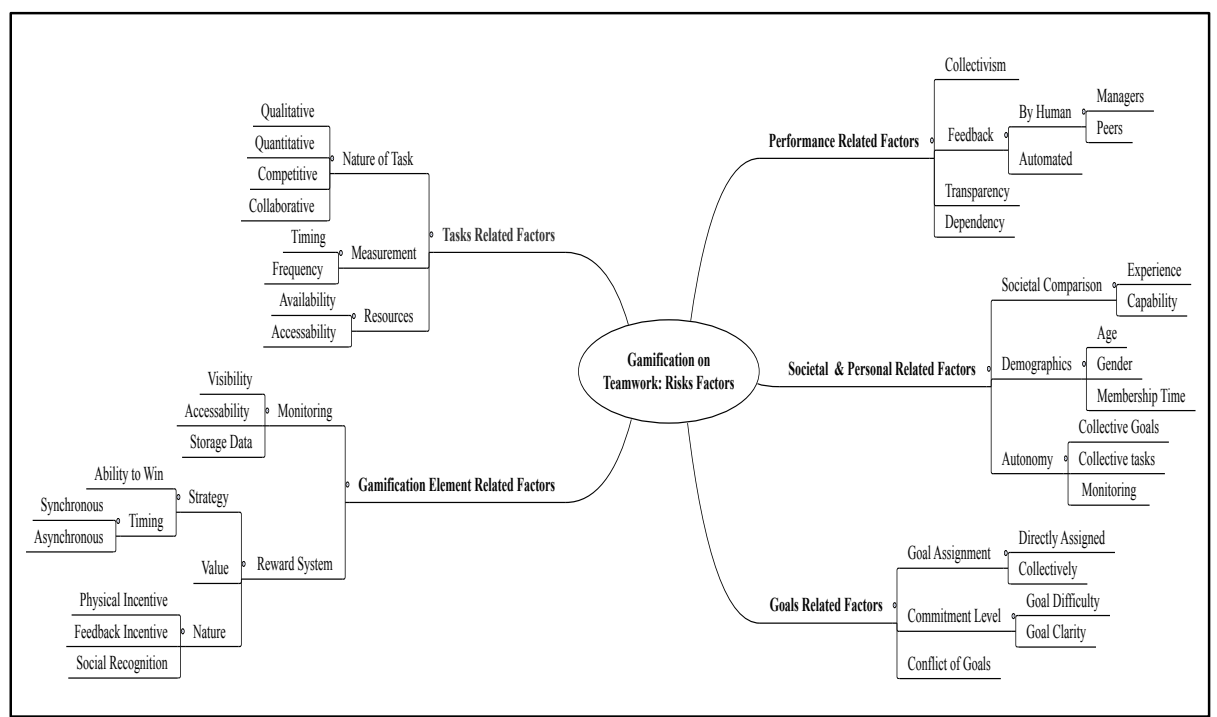

Fig. 1. Conceptualisation of Gamification Risk Factors to Teamwork

\subsection{Performance Related Risk Factors}

Performance is defined as "scalable actions, behaviours and outcomes that employees engage in or bring about that are linked with and contribute to organisational goals" [25]. Performance monitoring is commonly used in organisations and has become widely pervasive with the aid of digital tools [26]. While a principal aim of gamification in an enterprise context is to increase staff performance, we found that this could lead to the following four main risk factors.

Performance Collectivism. Gamification elements, using rewards and feedback on the collective performance of staff, might have a negative influence on the level and quality of collaboration among them. Risks of free riding occur when some team members tend to perform less well as they receive rewards equal to others, regardless of their individual performance. Moreover, risks can be seen when some team members work only to meet the minimum task requirements without paying enough consideration to the level of quality of their work. Although the collective performance is needed for the sense of teamwork, these situations might affect the work collaboration and create a risk in the workplace. In other words, solving such issue requires mitigation techniques which support a sense of auditing and checking strategies, rather than just avoiding collective performance tasks.

Performance Feedback. Feedback related to staff performance is a vital element of motivation, but it may also contribute to risks related to the quality of teamwork environment. An example is a badge or an avatar representing the current status of work quality. The main risk here is the misjudgement of performance. In a teamwork environment, feedback can be based on self-comparison, i.e. comparing performance to one's own performance in the past, peer-comparison feedback, i.e. comparing a per- 
son to others in their team, or collective-comparison feedback, i.e. comparing teams' performance to each other.

Our results showed different preferences about receiving performance feedback which shall be met to avoid risks. The source of feedback is the primary factor. Feedback can be generated by managers based on human-made judgments or software based on algorithms. Feedback from a human is seen to overcome the limitation of machines of measuring performance only based on the software-monitored performance indicators, e.g. number of calls answered but without looking at the quality and difficulty of the issue. Feedback from machines would suit the performance of tasks which are uniform and quantity based. It can also be preferred when objective measures are provided, e.g. customer feedback and rating. Manager feedbacks can reduce risks when the task is quality oriented and uneasily measured by machines. To reduce these risk, a blended approach can also be needed, e.g. when managers moderate the judgments made by the software. Besides the perceived misjudgement in feedback, clustering groups is another risk which can stem from feedback based on collective performance in teamwork. Top performers members may form their own teams and win. Moreover, feedback can be associated with past performance, e.g. examples of the previous behaviour in a task which might help to ease the future work [27]. In a teamwork environment, receiving such type of feedback may have a negative influence on staff that recently joins the team. It may lower self-esteem or make them less motivated to engage with the team.

Performance Transparency. Transparency of a gamification system collected performance data, and judgments derived from processing such data, manifests itself in three ways; transparency to managers, transparency amongst acquaintances involved in or doing the same task and, finally, transparency with staff in the department or the organisation. Although performance transparency can mitigate risks about perceived unfairness and conspiracy, it seems that several ethical and moral concerns arise as a result of it [28]. There is a fine line between transparency as an enabler for trust in a gamification system and as a counterproductive comparison and pressure tool. For example, disclosing the number of calls answered and points earned by each agent can increase competition and improve performance but, at the same time, it may convert sales representatives to set their performance goals based on other staff performance rather than the company target. In the observed call centres, performance transparency causing staff to be featured on the leaderboard, did not appeal to those who "did not like to be known as a top performer because others start to come to their desk and keep asking help". Transparency can increase the chance of anchoring bias among them by looking at each other's performance as a benchmark rather than realising their own strengths and skills and aiming to employ them in better-suited tasks.

Performance Dependency. The likelihood of risks in a teamwork environment increases when gamification techniques monitor and reward staff performing tasks which cannot be fully achieved independently. In the case of our call centre observations, risks of frustration and tension increased when an agent from the customer calls team needed support from a busy IT team to close a customer complaint. This can give rise to bribes, where a person may need to offer something in return to their 
dependees to get the gamification reward [1]. Addressing this issue, we should design gamification mechanics in a way that recognises potential deadlocks with the ultimate goal of not affecting the level of assistance required between staff.

\subsection{Societal and Personal Related Risk Factors}

Societal factors relate to the effects of a behaviour or a perception in relation to other staff, while personal factors relate to traits and inherent characteristics of staff.

Societal Comparison. Comparing staff with different capabilities and experiences, especially on a competitive basis, is a significant risk for a gamification system. Lowering self-esteem and intimidation are examples of such risks. Comparison is an essential game mechanics. Its design should seek to incorporate the differences between subjects, and measure their progress in a relative way.

Demographics. Age, gender and team membership duration influence acceptance and attitude towards games and gameplay applied to teamwork [29,30]. It can be argued that: "being with younger members in the same teamwork is frustrating, as they have better ability in digital techniques and their chance of winning the reward is higher". It can further be argued, that the appreciation of rewards of social benefits and collaborative nature, and those of competitive nature, can differ by gender [31]. The novelty effect of gamification technology means it can be initially exciting for new members, but become less useful for those with more extended experience [32].

Autonomy. Being obliged or pressured to be part of a gamification system in a prescriptive way can be detrimental [28]. Self-determination theory states that autonomy is one of the human psychological needs [33]. Flexibility and freedom of choice in tasks and goal allocation, primarily when performed collectively within groups, can encourage better teamwork collaboration, and reduce the likelihood of conflicts. For example, as identified in the result of this study that, pre-defined steps in a gamification tunnelling based technique, e.g. progress bar with tasks and milestones, might be preferred by staff who prefer serialism. Alternatively, staff who have higher autonomy and prefer holism may experience such monitoring and feedback as negative reinforcement.

\subsection{Goal Related Risk Factors}

The results identified some risks which can be introduced to the teamwork environment can be related to the goals factors, either main gamification goals, e.g. increase staff performance or personal staff goals, e.g. winning rewards.

Goal Assignment. Goals in teamwork can be assigned directly such as by a manager, or collectively among team members. Assigning goals might affect the motivation to perform a task. For instance, "the directly-assigned goals make staff working like a machine and affect their creativity in a task and the interest to perform it". On the other hand, in collective goal assignment, staff with high self-efficacy and confidence in their skills and ability to reach goals have more influence in setting goals for the team [34] and this result in stress to others afterwards. Staff with high self-efficacy would prefer more challenging goals than staff with lower self-efficacy [34]. Hence, managing the participation in goal setting is a key to set participatory goals. 
Commitment Level. Staff with higher self-efficacy tend to be committed more to assigned goals than those with lower self-efficacy [34]. In teamwork, lack of commitment to goals is strongly related to the level of performance in a task [35]. This is affected by two factors; goal difficulty and goal clarity.

Goal Difficulty. This indicates "a significant drop-off in performance as goal commitment declined in response to increasingly difficult goals" [36]. Moreover, there is a contradictory relationship between goal commitment and goal difficulty [36, 37]. Our study showed that in gamification teamwork where goals have been set collectively or via managers, the possibility of staff facing difficulties or discomfort in achieving goals is high. Consequently, such difficulties might affect their engagement with the team and create risks like lowering self-esteem and deviation from the primary goal.

Goal Clarity. It refers to the metrics and steps required to consider a goal achieved. Lack of clarity is another source of risk in gamification which might have an impact on staff's ability, intention or desire to commit to a goal. An example of this would be the case of adding a progress bar to motivate a call centre agent to help a client in completing an online registration form, but without clearly explaining why the client is given the help, or what system is used to evaluate the outcome.

Conflict of Goals. One of the primary reasons for having ethical and well-being issues in gamification systems is its potential conflict between stakeholders interests [38]. In a teamwork environment, conflict of goals can occur with a collectively assigned goal. This might affect the gamification system and cause staff to have a lack of engagement or a lack of interest in a task, failing to achieve the system goal. A participant stressed the conflict between being "on probation and having to perform well to get the job permanently, and being with staff who already passed their probation and have different goals in the system". This can have an effect on the performance, such as working extra hours and doing other staff tasks who are not under the same pressure, to appear on the leaderboard and prove efficiency.

\subsection{Task Related Risk Factors}

Engaging staff more successfully with a task is a key objective of a gamification system. The result of this study indicated gamification risks on team working stemming mainly from the characteristics of the task being subject to gamification techniques. For example, applying a gamification element such as a leaderboard - which follows a competitive ecology - to a collaborative task could have a negative impact on the intra-group relationships. In the following section, we explore three task-related risk factors about gamification in teamwork.

Nature of Task. A quantitative based task might introduce a risk such as reduce the quality of the work. For example, customer satisfaction may suffer if the reward is based on the number -rather than the quality - of customer calls. In quality tasks, the risk can be seen by the lack of clarity in setting task specification and requirements. In other words, one way to judge staff performance in quality based tasks is the systematic performance judgment based on electronic monitoring or feedback; this might 
increase the chance of unfairly judge staff performance, e.g. using predesigned automated measurements. Participants argued that: "it is unfair to be judged only based on monitoring customer calls", implying that the work required cannot be accurately reflected solely by the actual effort required. They added: "the quality might be affected by a variety of elements like the level of difficulty and clarity in customers', requests as some are easier than others".

Also, risks might also occur if the task is of a competitive nature. Our analysis of the observation notes suggested that adding a gamification element to a competitive task can still affect the required level of collaboration among staff in the work environment. For example in the call centre, staff may choose not to share a good solution for common customers issue with their colleagues to increase their chance to uniquely and efficiently solve more customers complains and win the reward. Similarly, risks also can occur when adding a gamification element to a collaborative task. Our study indicated that a situation like social loafing, where individuals reduce their effort when working with a group and rely on others, has a high chance to appear if a collective task is motivated using inter-group competition.

Measurement. Measuring staff performance is essential to decide on rewards and feedback provided through gamification elements. Failure or limitation in such measurement can lead to side-effect on the teamwork environment. Two main factors are duration and frequency.

Timing. The real-time ability in gamification elements to track staff performance and send real-time feedback makes the duration of the measurement a source of risk, e.g. unfair judgement. For instance, if the measurement of staff engagement in answering a call is based on real-time voice analysis, such as the level of comfort of the client and the friendliness of the call agent, this might lead to unfair judgments. The staff could be affected via various elements, e.g. difficult customer or inquiry during the performance measurement duration in such motivational technique which might cause unfair judgment of their engagement in a task. A participant argued that:" judgment based on real-time observation of our performance might be affected by reasons like difficult customer or issue which could increase the possibility of bias".

Frequency. Some staff may be more motivated by a daily performance report, while others would prefer it at the end of the task, as evidenced by one participant who stated: "I prefer to be measured on a monthly basis to be motivated more as I might feel frustrated if I know the result before, like based on weekly or daily results". Hence, having both kinds of staff on the same team might have adverse effects on the team.

Resources. The availability and accessibility of resources are essential factors which assist staff in performing tasks more effectively. For example, LiveOps, an application for online call centres, facilitates the real-time recording of customers' personal details. Hence, in competitive teamwork environments, where staff compete to win rewards, access to such resources plays a vital role in both individual and team performance. As a result, careful consideration is needed to avoid introducing unwanted $\underline{\text { bias }}$ which could affect staff motivation. In the call centre observed, it was noticed that some tasks required external resources, i.e., resources from another, potentially competing, team. This made the possibility of winning the gamification reward de- 
pendent on resources from others, which affected the gamification system and created risks. One participant in the call centre commented that "some tasks required external resources from others which might affect the competition". Similarly, in such situations, where there are team metrics and team rewards, the likelihood of other negative behaviours such as work intimidation is increased.

\subsection{Gamification Design Related Risk Factors}

Gamification elements refer to those motivational techniques which can be added to the environment to engage, motivate, and monitor staff involvement in the workplace, to increase their engagement and achieve business goals. Commonly used examples of such elements are points, leaderboards, badges and missions. The digital nature of the motivational elements adds more effective features such as real-time monitoring and feedback, and tractability and traceability of staff's performance. However, the gamification element also introduces risks, especially around the lack of validation and implementation strategies. For example in the call centre observed, some staff continued to work without taking breaks, due to their perception that their performance - as shown on the leaderboard - was being scrutinised by other staff in the department. This might have a negative impact on the quality of their work or possibly their well-being. Below, we discuss the two main risk factors we identified about the gamification elements.

Monitoring. Monitoring is an essential mechanism of most gamification elements which support the enhancement of staff performance. It can help staff to engage more in a task by regulating their performance or behaviours. However, monitoring can also have negative consequences in a teamwork environment, due to the following factors.

Visibility. It was noticed in the call centre observed that some staff had concerns regarding what would be visible to colleagues, either in the same or other teams. For example, displaying the number of calls each team member has answered could impact the coherence of the group via dividing staff into new intra-groups based on their performance in a task [39]. Staff preferred their current performance to be visible to their managers or themselves only, with the choice to share it with others.

Accessibility. In a gamification system, decisions are made based on information gathered from the environment. In a teamwork setting, the accessibility of staff information in the monitoring technique might have a negative influence on the teamwork. For example, one agent in the call centre commented: "I prefer to have the ability to decide what the system can access regarding my personal information and also what my team members are able to access". Risks like infringe staff autonomy can result from monitoring staff as they perform a task. For example, a supervisor in the call centre mentioned that they could access and monitor staff calls at any time. Some staff in the call centre agreed that they "prefer to know the accessibility time and the sort of information that has been collected".

The Storage of the Data. The staff could have concerns about the type of information stored on the system and the access to such information. In a teamwork environment, 
a risk can be seen when performing competitive tasks, where teams might have access to data stored by other teams which might have a negative effect on the gamification system, i.e. ineffective competition. For example, in a fitness application where people are motivated by comparing their performance with peers, making the stored history available to others might affect the competition and kill the joy of the system.

Reward System. The primary motivator of most gamification elements is the reward mechanism. A reward system is another essential factor of the gamification that needs careful consideration to avoid adversely affecting the teamwork. Within the workplace, the gamification reward takes the form of physical rewards, feedback, or public recognition. The reward might be a source of risks in a gamification system due to the following factors.

The Strategy. Staff have a variety of preferences regarding how they want to be rewarded, which makes the strategy a potential risk factor in a teamwork environment. The strategy of the reward can be seen as a risk when the strategy introduces a sense of perceived exploitation in the workplace. Exploitation can occur when staff feel that their extra performance and quality of work are not rewarded. For example, this can happen when the reward strategy in place only rewards the best performance. It would be preferable, in such circumstances, to have a gamification strategy which recognised everyone's performance, and hence, supported teamwork.

The Ability to Win the Reward. Staff with low self-esteem might have difficulty to participate in tasks in teamwork when the ability to win the reward is high, which could have a negative effect on the coherence of the team. In the call centre observed, staff could be classified into two categories, those who preferred to be motivated to win the reward using a challenge, and those who found it a source of obstruction. Mixing both types of staff in the same team or same competition might affect the system and create a risk such as lack of group cohesion in the workplace.

The Timing. A reward in a gamification system can either be synchronous or asynchronous. In real-time, the system allows managers to provide synchronous rewards, such as real-time feedback. This can happen when the required goal of the task is achieved, even before the end of the task time. One example would be answering the target number of calls before the end of the week or month. In the call centre, some staff stated that they: "prefer to be rewarded after finishing the task not to lose my motivation". However, a participant mentioned that "I sometimes need extrinsic motivation while performing a task to increase my intrinsic motivation". In teamwork, especially in competitive tasks, receiving synchronous feedback might affect the quality of the work negatively, especially when staff feel they have little chance of winning the competition.

The Value. A low-value reward might demotivate staff, limiting their engagement with a task, and affecting their quality of work. The value of the reward should reflect the actual effort staff contribute to a task. In teamwork, for collaborative tasks, the collaboration might be affected when some staff are less motivated to participate in the task due to their perception of low-value rewards. The overall finding indicates 
that the value of the reward is recommended to be heavily connected to the level of performance staff required to win the reward, to avoid the risk of reducing motivation.

The Nature of the Reward. This can have different forms, e.g. physical reward, feedback, or public recognition. In the call centre observed, all of these rewards were used to motivate staff. The impact of the nature of the reward is heavily connected with the personality of individuals. The differences in staff preferences about the nature of reward might cause a risk in teamwork effectiveness, which can, in turn, affect the achievement of business goals. Some agents commented that "we feel more motivated to participate in a task with physical rewards rather than other types of rewards". Risks like negative participation might occur in the system applied in teamwork when some members are less motivated as a result of the nature of the reward.

\section{Gamification Risks Vs Risk Management Strategies}

The analysis in Section 3 demonstrated the need for careful consideration and design principles when applying gamification elements and managing their risks on teamwork. In this section, we link the risks discussed in Section 3 with a set of 22 strategies proposed in [14] to detect and manage the potential effects of the gamification system on teamwork. A focus group with seven participants from different professional and academic background was conducted to map identified risks to mitigation strategies. Table 2 gives a summary of the findings. Risk management strategies can be applied (i) to detect and identify risks, (ii) to prevent or reduce the chance of the risk, (iii) to resolve the risks or alleviate their effect when it happens.

Risks about staff performance when doing a job as a group, e.g. free-riding, social loafing and work intimidation, can be detected and alleviated using strategies which employ auditing, member checking and random monitoring. Gamification design strategies like a reward for helping others and reward for of individual contribution can be then applied as resolution strategies. Strategies revolving around setting rules and agreements like common ground rules and commitment can be used to prevent or reduce the likelihood of risks related to $\underline{\text { misjudgement }}$ and honesty like anchoring bias and exploitation.

The observation and interviews in the two call centres involved in this study showed that some risks need to be managed during the stage of gamification design and its introduction to a teamwork environment, whilst other risks might need to be managed when they or their indicators appear while the system is in operation. Some risks can benefit from being managed at both times. Management strategies that help setting up agreements and rules amongst multidiscipline staff involved in gamification would fit more at the design stage. Practitioners and managers interviewed agreed that strategies for collective agreement and participatory decision making like, get everyone involved, commitment, voting are best applied at the design stages to increase the intrinsic motivation and acceptance of a gamification system. This is due to taking part in its design process and hence reducing the chance of risks like work to meet the minimum requirements, bribe for exchange, social loafing and free riding. While the system is already in operation, surveillance strategies like peer-rating, member checking and self-assessment can help to detect and possibly resolve risks 
related to measurements and rewarding such as misjudgements of performance and lack of engagement in collective tasks or goals.

\begin{tabular}{|c|l|}
\hline Risk & \multicolumn{1}{|c|}{ Exemplar of Mitigation strategy } \\
\hline Free-Riding & $\begin{array}{l}\text { Auditing, member checking, random monitoring, get everyone } \\
\text { involved, commitment, voting, common ground rules, reward } \\
\text { individual contribution }\end{array}$ \\
\hline $\begin{array}{c}\text { Meet the minimum } \\
\text { requirements }\end{array}$ & $\begin{array}{l}\text { Get everyone involved, commitment, voting, common ground } \\
\text { rules, norms }\end{array}$ \\
\hline $\begin{array}{c}\text { Performance } \\
\text { Misjudgements }\end{array}$ & Auditing, peer-rating, member checking, self-assessment, \\
\hline Clustering groups & Auditing, commitment, facilitator \\
\hline Lowering self-esteem & Reward for of individual contribution, random monitoring \\
\hline $\begin{array}{c}\text { Counterproductive } \\
\text { comparison }\end{array}$ & Auditing, Anonymity \\
\hline Negative pressure & Auditing, reward for helping others, reward individual contribution \\
\hline Anchoring bias & Common ground rules, commitment, transparency \\
\hline Bribe for exchange & Get everyone involved, commitment, voting, common ground rules \\
\hline Work Intimidation & $\begin{array}{l}\text { Auditing, member checking, random monitoring, reward for } \\
\text { helping others, norms }\end{array}$ \\
\hline Novelty effect & Anonymity, rotations sensitivity \\
\hline Deviation from goal & Reward for of individual contribution \\
\hline Lack of engagement & Peer-rating, member checking, self-assessment \\
\hline Reduce task quality & Reward for of individual contribution, random monitoring \\
\hline Social loafing & $\begin{array}{l}\text { Auditing, member checking, random monitoring, get everyone } \\
\text { involved, commitment, voting, common ground rules }\end{array}$ \\
\hline Infringe autonomy & Anonymity, managerial level monitoring, rotations sensitivity \\
\hline Kill of the joy & Anonymity, rotations sensitivity, random monitoring \\
\hline Exploitation & $\begin{array}{l}\text { Common ground rules, commitment, peer-rating, member } \\
\text { checking, self-assessment, transparency }\end{array}$ \\
\hline
\end{tabular}

Table 2. Gamification Risks vs Management Strategies

Finally, our strategies to manage risks raised a concern about the possibility of causing a domino effect, where a strategy might introduce or trigger more secondary unwanted risks and effects. For example, applying transparency strategy in staff performance as a risk management strategy could help to detect and alleviate risks in relation to misconception, conspiracy and unfairness such as, anchoring bias, misjudgements of performance and perceived exploitation. However, this strategy might introduce another risk like infringe autonomy, negative pressure and lowering selfesteem which might also trigger further risks such as reduced task quality and deviation from goal. Hence, this raises the need for a holistic method which utilises techniques like a participatory design, simulation and rehearsal for predicting scenarios, consensus building and catering for the multiple viewpoints.

\section{Conclusion and Future Work}

In this paper, we made the argument that gamification shall undertake a risk assessment and management process to cater for its potential side-effects on teamwork. As a first step towards proposing theory-informed methods for gamification risk manage- 
ment, the research we performed in this paper contributed with taxonomies of risks factors, exemplar risks and management strategies. In our future work, we will utilise this knowledge and develop a method for detecting gamification risks and assessing their mitigation strategies. This will add to the literature in risks assessment and augment approaches to risk management especially at the early stages of the systems development such as those proposed in $[19,40]$. Given the human-intense nature of gamification, we speculate our method to have a participatory nature and employee techniques that help exploration and speculation such as role-playing, rehearsal, simulation and scenarios.

\section{References}

1. Shahri, A., Hosseini, M., Phalp, K., Taylor, J., Ali, R.: Towards a Code of Ethics for Gamification at Enterprise. PoEM. 197, 235-245 (2014).

2. Forsyth, D.: An introduction to group dynamics. (1992).

3. Barata, J., da Cunha, P.R., Abrantes, L.: Dealing with Risks and Workarounds - A Guiding Framework. PoEM. 235, 141-155 (2015).

4. Alter, S., Sherer, S.A.: A General, But Readily Adaptable Model of Information System Risk. CAIS. (2004).

5. Muehlen, Zur, M., Rosemann, M.: Integrating risks in business process models. Presented at the ACIS 2005 Proceedings - 16th Australasian Conference on Information Systems December 1 (2005).

6. Suriadi, S., Weiß, B., Winkelmann, A., Hofstede, ter, A.H.M., Adams, M., Conforti, R., Fidge, C., La Rosa, M., Ouyang, C., Pika, A., Rosemann, M., Wynn, M.: Current research in risk-aware business process management-overview, comparison, and gap analysis. CAIS. 34, 933-984 (2014).

7. Vilpola, I., Ojala, M., Kouri, I.: Risks and Risk Management in ERP Project - Cases in SME Context. BIS. 179-186 (2006).

8. Zoet, M., Welke, R., Versendaal, J., Ravesteyn, P.: Aligning Risk Management and Compliance Considerations with Business Process Development. E-Commerce and Web Technologies. 5692, 157- (2009).

9. Stirna, J., Zdravkovic, J., Grabis, J., Sandkuhl, K.: Development of Capability Driven Development Methodology - Experiences and Recommendations. PoEM. 305, 251-266 (2017).

10. Morschheuser, B., Hassan, L., Werder, K., Hamari, J.: How to design gamification? A method for engineering gamified software. Information and Software Technology. (2018).

11. Kumar, J.: Gamification at Work - Designing Engaging Business Software. HCI. 8013 LNCS, 528-537 (2013).

12. Apter, M.J., Kerr, J.H.: Adult Play. Garland Science (1991).

13. Thiebes, S., Lins, S., Basten, D.: Gamifying Information Systems - a synthesis of Gamification mechanics and Dynamics. ECIS. (2014).

14. Algashami, A., Shahri, A., McAlaney, J., Taylor, J., Phalp, K., Ali, R.: Strategies andDesign Principles to Minimize Negative Side-Effects of Digital Motivation on Teamwork. PERSUASIVE. 10171, 267-278 (2017).

15. Saunders, M., Lewis, P., Thornhill, A.: Research Methods for Business Students. Pearson Education (2009).

16. Deterding, S., Dixon, D., Khaled, R., Nacke, L.: From game design elements to gamefulness - defining "gamification". Presented at the The th International Academic MindTrek Conference Envisioning Future Media Environments,(2011).

17. Ahn, von, L.: Games with a Purpose. IEEE Computer. 39, 92-94 (2006).

18. Fogg, B.J.: Creating persuasive technologies - an eight-step design process. 
PERSUASIVE. 350, 1 (2009).

19. Boehm, B.W.: Software risk management: principles and practices. IEEE Software. 8, 3241 (1991).

20. Friedman, B., Kahn, P.H., Borning, A., Huldtgren, A.: Value Sensitive Design and Information Systems. In: Early engagement and new technologies: Opening up the laboratory. pp. 55-95. Springer, Dordrecht, Dordrecht (2013).

21. Dion, K.L.: Group cohesion: From "field of forces" to multidimensional construct. Group Dynamics: Theory, Research, and Practice. 4, 7-26 (2000).

22. Shahri, A., Hosseini, M., Phalp, K., Taylor, J., Ali, R.: Exploring and Conceptualising Software-Based Motivation Within Enterprise. PoEM. 267, 241-256 (2016).

23. Saunders, M., Lewis, P., Thornhill, A.: Research Methods for Business Students. Pearson Education (2009).

24. Braun, V., Clarke, V.: Using thematic analysis in psychology. Qualitative Research in Psychology. 3, 77-101 (2006).

25. Viswesvaran, C., Ones, D.S.: Perspectives on Models of Job Performance. International Journal of Selection and Assessment. 8, 216-226 (2000).

26. Ball, K.S., Margulis, S.T.: Electronic monitoring and surveillance in call centres: A framework for investigation. New Technology, Work and Employment. 26, 113-126 (2011).

27. Liu, Y., Alexandrova, T., Nakajima, T.: Gamifying intelligent environments. Presented at the the 2011 international ACM workshop, New York, USA (2011).

28. Raftopoulos, M.: Towards gamification transparency: A conceptual framework for the development of responsible gamified enterprise systems. journal of gaming \& virtual worlds. 6, 159-178 (2014).

29. Greenberg, B.S., Sherry, J., Lachlan, K., Lucas, K., Holmstrom, A.: Orientations to Video Games Among Gender and Age Groups. Simulation \& Gaming. 41, $238-259$ (2008).

30. Griffiths, M.D., Davies, M.N.O., Chappell, D.: Breaking the stereotype: The case of online gaming. Cyberpsychology and Behavior. 6, 81-91 (2003).

31. Williams, D., Consalvo, M., Caplan, S., Yee, N.: Looking for Gender: Gender Roles and Behaviors Among Online Gamers. Journal of Communication. 59, 700-725 (2009).

32. Koivisto, J., Hamari, J.: Demographic differences in perceived benefits from gamification. Computers in Human Behavior. 35, 179-188 (2014).

33. Ryan, R.M., Deci, E.L.: Self-determination theory and the facilitation of intrinsic motivation, social development, and well-being. American Psychologist. 55, 68-78 (2000).

34. Locke, E.A., Latham, G.P.: Building a practically useful theory of goal setting and task motivation: A 35-year odyssey. American Psychologist. 57, 705-717 (2002).

35. Locke, E.A., Latham, G.P., Erez, M.: The Determinants of Goal Commitment. The Academy of Management Review. 13, 23-39 (1988).

36. Erez, M., Zidon, I.: Effect of goal acceptance on the relationship of goal difficulty to performance. Journal of Applied Psychology. 69, 69-78 (1984).

37. Locke, E.A.: Relation of goal level to performance with a short work period and multiple goal levels. Journal of Applied Psychology. 67, 512-514 (1982).

38. Kim, T.W., Werbach, K.: More than just a game: ethical issues in gamification. Ethics Inf Technol. 18, 157-173 (2016).

39. Shahri, A., Hosseini, M., Phalp, K., Taylor, J., Ali, R.: How to Engineer Gamification: The Consensus, the Best Practice and the Grey Areas. Journal of Organizational and End User Computing. 31,(2019).

40. Asnar, Y., Giorgini, P., Mylopoulos, J.: Goal-driven risk assessment in requirements engineering. Requirements Eng. 16, 101-116 (2010). 